experimental Candida endophthalmitis. Antimicrob Agents Chemother 1987; 31(1): 6-10.

6 Bagnoud M, Baglivo E, Hengstler J, Safran AB, Pournaras CJ Leuenberger P. Endogenous fungal endophthalmitis: results of antifungal treatment with and without vitrectomy. Klin Monatsbl Augenheilkd 2001; 218(5): 398-400.

7 Pournaras CJ, Issoua D, Saravelos S, Sunaric G. Candida chorioretinitis: current therapeutic approach. Klin Monatsbl Augenheilkd 1994; 204(5): 334-336.

8 Torres Perez JD, Olea Cascon J, Crespo Ortiz P, Uriarte Estefania F, Tortajada Goitia B, Perez-Salvador JL. Oral itraconazole for treatment of a Candida parapsilosis endophthalmitis case. Arch Soc Esp Oftalmol 2004; 79(4): 181-184.

\section{Gunasekera and L Herbert}

Department of Ophthalmology, Queen Elizabeth II Hospital, Welwyn Garden City, Hertfordshire, UK

Correspondence: L Herbert,

Department of Ophthalmology,

Queen Elizabeth II Hospital,

Welwyn Garden City,

Hertfordshire AL7 4HQ, UK

Tel: + 44 1737231752;

Fax: + 441737231736

E-mail: Iherbert@doctors.net

Work not previously presented

Other interests: none declared

Eye (2007) 21, 110-111. doi:10.1038/sj.eye.6702417; published online 12 May 2006

Sir,

Posterior retinal detachment without macular hole in high myopia: visualization with en face optical coherence tomography

During degenerative myopia, a congenital scleral weakening determines progressive globe enlargement, axial elongation, and formation of posterior staphyloma. In his series of 250 highly myopic patients, Curtin ${ }^{1}$ has classified the posterior staphyloma in 10 groups: type 1 , localized to the posterior pole; type 2 , involving the macula; type 3, peripapillary staphyloma; type 4, nasal staphyloma; type 5, inferior staphyloma; and types 6-10, mixed staphyloma. Posterior retinal detachment without macular holes has been recently described in high myopia with optical coherence tomography (OCT). ${ }^{2,3}$ The causes of the macular detachment have not yet been clearly elucidated, although vitreal traction and myopic stretching of the eye seem to play a major role in the pathogenesis. Visual acuity may range from counting fingers to $20 / 20$. The recently introduced OCT ophthalmoscope provides coronal OCT scans (OCT C-scans) of the retina. ${ }^{4-6}$

\section{Case report}

A 44-year-old male patient underwent a regular checkup of high myopia. In both eyes, best-corrected visual acuity was 20/25 and refractive error was $-11 \mathrm{D}$. Anterior segment was unremarkable OU and the intraocular tension was $19 \mathrm{mmHg}$ OU. At fundoscopic examination, choroidal pallor, and tessellation, focal areas of deep choroidal atrophy and type I staphyloma were present in both eyes. Examination with en face ophthalmoscope (OCT/SLO, Ophthalmic Technologies Inc., Toronto, Canada) was performed. Longitudinal B-scan OCT (Figure 1a) showed in the left eye a retinal detachment extending from the peripapillary area to the macula without interruption. In the maculopapillary bundle (MPB) multiple hyporeflective cysts in the inner retina were detected. Inner retinal surface at this site was slightly hyper-reflective. Foveal thickness was consistently increased $(365 \mu \mathrm{m})$ and thinning of the foveal neuroepithelium was present. The posterior hyaloid was partially detached and inserted in the papillary area and into the fovea. Coronal C-scan OCT of the same eye (Figure 1b-h) showed a large hyporeflective subretinal space involving the whole posterior pole from nasal to the disc to beyond vascular arcades, whose outer limits were clearly detectable. C-scans of the inner retina showed both the partial posterior hyaloid detachment and the cystic degeneration in the MPB. The surface of the cystic area appeared wrinkled and hyper-reflective. In the right eye, en face OCT examination detected incomplete PVD without macular traction and without any sign of retinal detachment. Visual field performed with Humphrey 30-2 programme was normal OU.

\section{Comment}

Foveal retinal detachment in high myopia may be associated or not with a macular hole. ${ }^{2,7}$ In recent years, posterior detachment without macular hole has been evaluated with traditional B-scan OCT and the reported frequency ranges from $9 \%$ in a series of 78 eyes to $34 \%$ in a series of 19 patients. ${ }^{2,3}$ The recently introduced en face OCT ophthalmoscope combines OCT and confocal ophthalmoscopy, allowing visualization of the retina in both longitudinal and coronal scans. In our case, the detachment of the whole posterior area had not been recognized at fundus examination and the en face OCT has allowed the fine visualization of its lateral limits. Furthermore, the overlaid red free/confocal OCT C-scan 
has shown the relationships of the fovea and the disc with the outer limits of the detachment in the coronal plane.

Cystic inner retinal degeneration was clearly detectable at both longitudinal B-scan and coronal
C-scan. The cystic changes in the inner retina might represent either a first step towards the development of an inner retinoschisis after anteroposterior stretching of the retina or a thickened epiretinal membrane. This last hypothesis could explain the correspondent slight hyper-

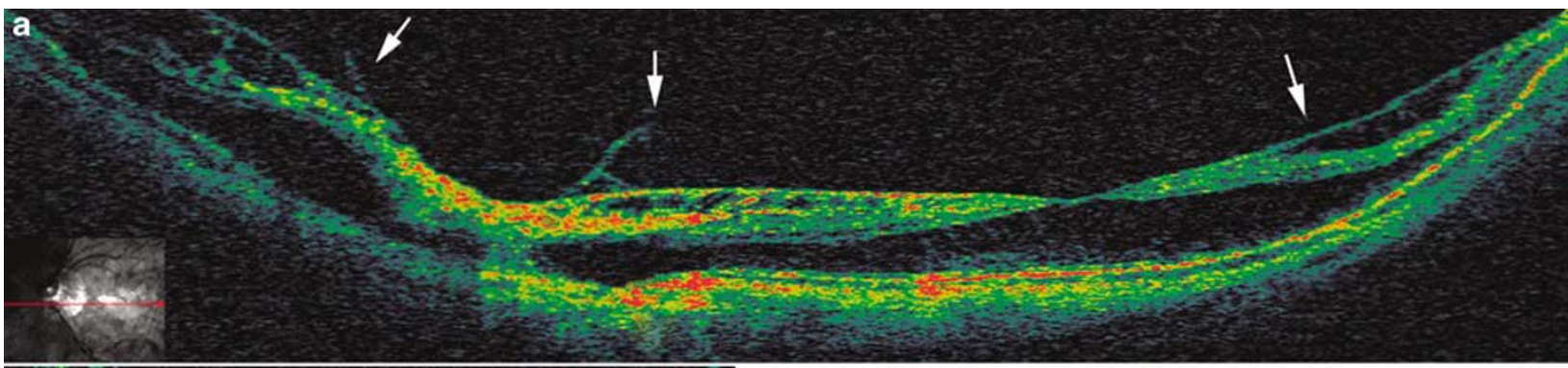

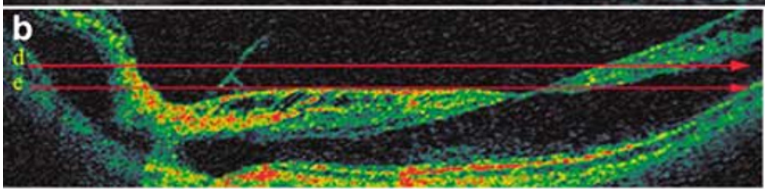

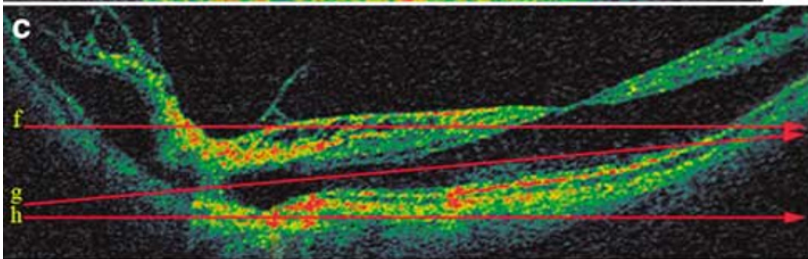

e

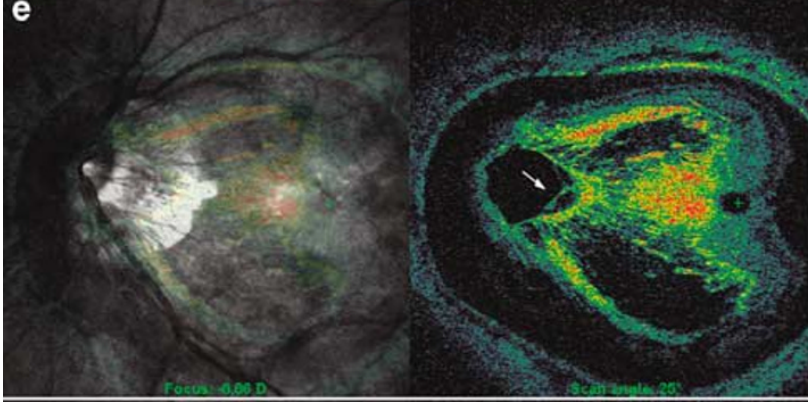

9

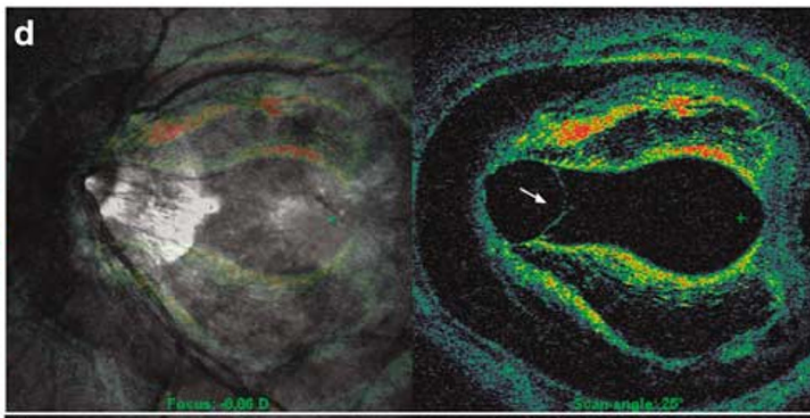

f
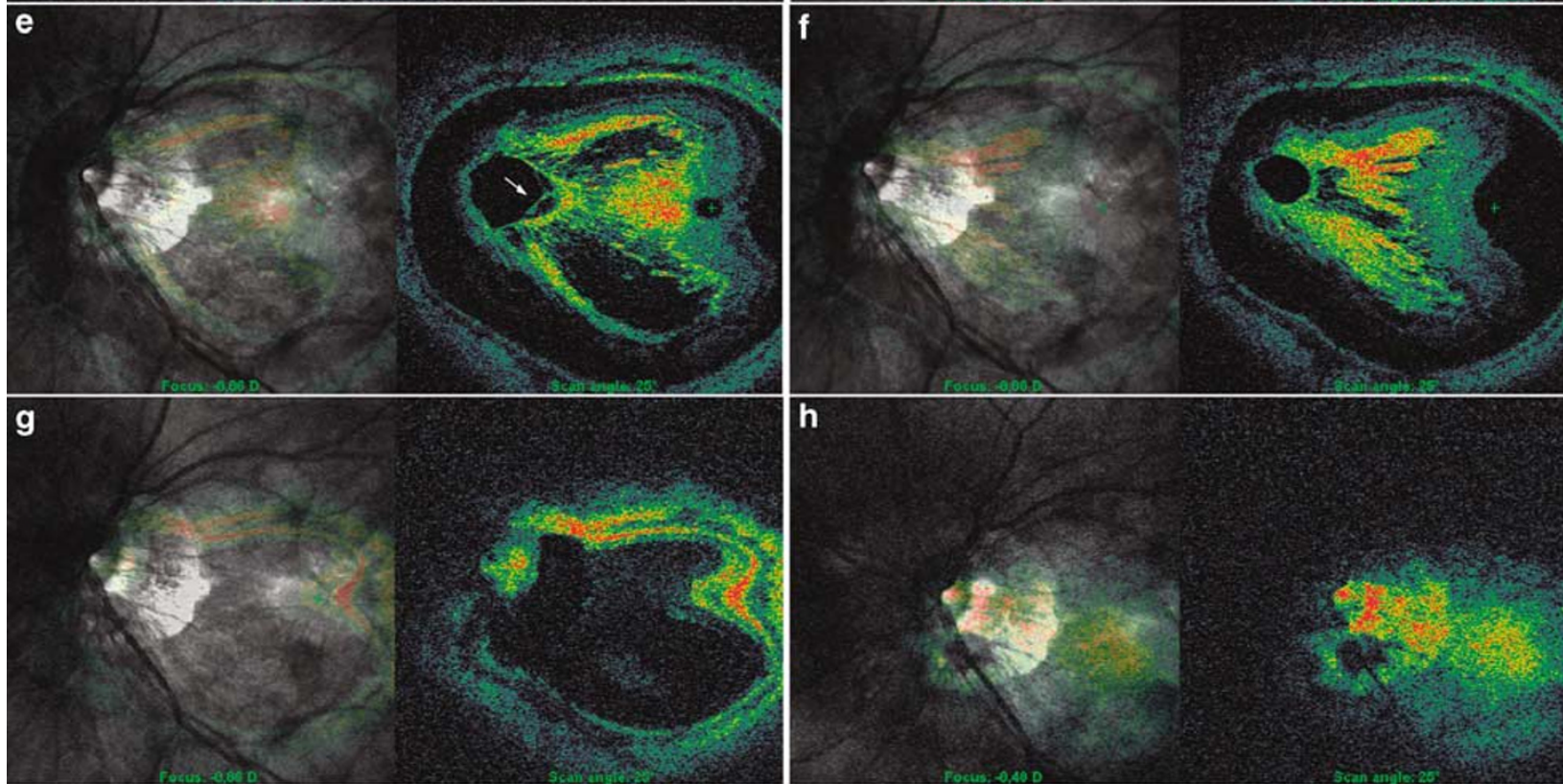

h

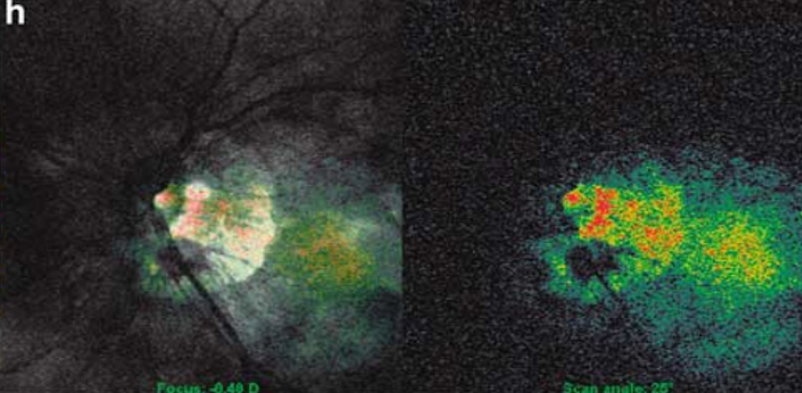

Figure 1 (a) Composite image of longitudinal OCT B-scans ( $8 \mu \mathrm{m}$ axial resolution) showing the wide retinal detachment in the absence of a macular hole, the microcystic-like intraretinal degeneration in the MPB whose inner surface appears slightly hyperreflective, and the adherence of the partially detached posterior hyaloid at the optic disc and the temporal fovea (arrows). (b and c) Diagrams showing the location of the coronal scans on the corresponding cross-sectional B-scan. The two B-scan images slightly differ as a consequence of the tilting of the eye. (d-h, left) Overlay of scanning laser ophthalmoscopy (SLO) image and C-scan obtained with a default application; (right) C-scan image. The anteroposterior scans show the ring of adherence of the posterior hyaloid to the optic disc (arrows) and the posterior retinal detachment, which involves the whole central area and whose outer limits are clearly detectable. In the MPB, the hyper-reflective retinal wrinkling ( $c$ and d) corresponds to the intraretinal cysts observed at B-scans. The green cross represents the foveal area. 
reflectivity of the inner retina at B-scan OCT and the hyper-reflective wrinkling in the MPB observed at OCT C-scan. In our case, both B- and C-scans have shown foveal traction from the incompletely detached posterior hyaloid. Together with ocular stretching, tangential epiretinal tractions are likely to have a role in the formation of the posterior detachment. The frequency of association between tractions and retinal detachment without macular hole ranges in literature from $19^{7}$ to $46.4 \%{ }^{8}$

Despite the wide extent of the posterior detachment, our patient showed an almost unremarkable visual acuity and a normal visual field. The relatively good visual acuity seems to be a characteristic of a detachment without macular hole. ${ }^{3}$ As the detachment in these cases is usually shallow, oxygen and nutrient diffusion from the choriocapillaris to the photoreceptors may be sufficient for them to survive to some extent. Thus, regular examination with OCT should be performed to institute preventive therapies in case of macular hole formation and progressive visual decrease.

In conclusion, the use of the OCT ophthalmoscope in high myopia may provide additional informations not readily available with conventional imaging techniques. Further studies are needed to investigate these features in a larger series.

\section{References}

1 Curtin BJ. The posterior staphyloma of pathologic myopia. Trans Am Ophthalmol Soc 1977; 75: 67-86.

2 Takano M, Kishi S. Foveal retinoschisis and retinal detachment in severely myopic eyes with posterior staphyloma. Am J Ophthalmol 1999; 128: 472-476.

3 Baba T, Ohno-Matsui K, Futagami S, Yoshida T, Yasuzum, Kojima A et al. Prevalence and characteristics of foveal retinal detachment without macular hole in high myopia. Am J Ophthalmol 2003; 135: 338-342.

4 Podoleanu AG, Seeger M, Dobre GM, Webb DJ, Jackson DA, Fitzke $\mathrm{F}$ et al. Transversal and longitudinal images from the retina of the living eye using low coherence reflectometry. J Biomed Opt 1998; 3: 12-20.

5 van Velthoven ME, Verbraak FD, Garcia PM, Schlingemann $\mathrm{RO}$, Rosen RB, de Smet MD. Evaluation of central serous retinopathy with en face optical coherence tomography. Br J Ophthalmol 2005; 89(11): 1483-1488.

6 van Velthoven ME, Verbraak FD, Yannuzzi LA, Rosen RB, Podoleanu AG, de Smet MD. Imaging the retina by en face optical coherence tomography. Retina 2006; 26(2): 129-136.

7 Benhamou N, Massin P, Haouchine B, Erginay A, Gaudric A. Macular retinoschisis in highly myopic eyes. Am J Ophthalmol 2002; 133: 794-800

8 Panozzo G, Mercanti A. Optical coherence tomography findings in myopic traction maculopathy. Arch Ophthalmol 2004; 122(10): 1455-1460.
R Forte ${ }^{1}$, F Pascotto ${ }^{2}$, E Soreca ${ }^{3}$, G Cusati $^{3}$

and $G$ de Crecchio'

${ }^{1}$ Eye Department, University Federico II, Naples, Italy

${ }^{2}$ Eye Department, Second University, Naples, Italy

${ }^{3}$ Eye Department, Gepos Hospital, Telese (Bn), Italy

Correspondence: R Forte,

Dipartimento di Scienze Oftalmologiche,

Università Federico II,

Via Pansini 5, Naples 80131, Italy

Tel: + 390817463731 ;

Fax: + 390817462383

E-mail: raifor@hotmail.com

Eye (2007) 21, 111-113. doi:10.1038/sj.eye.6702418; published online 7 July 2006

Sir,

Late-onset capsular block syndrome without lens displacement

Capsular block syndrome (CBS) is a rare complication that occurs with posterior chamber in the bag intraocular lens (IOL) placement, with continuous curvilinear capsulorhexis. ${ }^{1}$ It classically presents with forward displacement of IOL and associated myopic shift, ${ }^{2,3}$ and usually occurs in the intra- or early postoperative period. ${ }^{4}$ We report a case of late CBS secondary to the liquefied after-cataract without the lens displacement or change in the refractive status.

\section{Case report}

An 85-year-old lady presented to the eye clinic with a history of recent deterioration of vision in her left eye. She had undergone phacoemulsification 5 years ago. The operation was uneventful with continuous curvilinear capsulorhexis of moderate size and one-piece posterior chamber lens implant. She was not at high risk for CBS. The postoperative recovery was good with the best-corrected visual acuity being $6 / 6$.

On examination best-corrected visual acuity in the affected eye was 6/9. Slit-lamp biomicroscopy showed thick and taut anterior capsule adhered to the lens at the margin of capsulorhexis. The capsular bag was distended and bulged back into the vitreous with entrapped milky white fluid of liquefied after-cataract between the posterior capsule and the lens. The lens was in situ 